Case Report

\title{
Recurrent Herpes Zoster Ophthalmicus Preceded by Anabolic Steroids and High-Dose L-Arginine
}

\author{
Stephen A. LoBue $\mathbb{D}^{1,2}$ Adam Goldman $\mathbb{D}^{1,},{ }^{1}$ Richard A. Giovane $\mathbb{D}^{\circ},{ }^{3}$ Stacy M. Carlson $\mathbb{D}^{4}$ \\ Michael Bivona $\mathbb{D}^{1},{ }^{1}$ Sinan Albear, ${ }^{1}$ and Thomas D. LoBue ${ }^{2}{ }^{2}$ \\ ${ }^{1}$ Department of Ophthalmology, SUNY Downstate, Brooklyn, NY 11203, USA \\ ${ }^{2}$ LoBue Laser \& Eye Medical Centers, Murrieta, CA 92562, USA \\ ${ }^{3}$ LV Stabler Hospital, Greenville, AL 36037, USA \\ ${ }^{4}$ Montefiore Medical Center, Bronx, NY 10467, USA
}

Correspondence should be addressed to Stephen A. LoBue; slobue87@gmail.com

Received 29 August 2020; Accepted 30 September 2020; Published 29 December 2020

Academic Editor: Nicola Rosa

Copyright (c) 2020 Stephen A. LoBue et al. This is an open access article distributed under the Creative Commons Attribution License, which permits unrestricted use, distribution, and reproduction in any medium, provided the original work is properly cited.

\begin{abstract}
Purpose. To report a case of a 34-year-old male with recurrent herpes zoster ophthalmicus (HZO) preceded by a 6-week cycle of anabolic steroids and high-dose amino acid supplementation. Case Presentation. A 34-year-old man presented to our institution for left eye pain for one week associated with a vesicular rash in the V1 dermatome, respecting the midline. The patient had no significant past medical or past ocular history, including systemic immunosuppressive agents or HIV. However, prior to the onset of his symptoms the patient had completed a 6-week course of anabolic steroids including trenbolone, deca-durabolin, and testosterone as well as high-dose arginine supplementation averaging more than 40 grams a day. The best-corrected vision was 20/25 OS with slit-lamp examination remarkable for punctate staining and pseudodendrites at 6 o'clock, outside the visual axis. The patient was treated with oral acyclovir $800 \mathrm{mg}$ five times a day for seven days along with prednisolone QID and moxifloxacin QID which was tapered over a month. Four months after resolution, the patient developed a recurrent HZO keratitis preceded by another cycle of anabolic steroids and amino acid supplementation. Conclusion. In vitro L-arginine supplementation has been associated with the proliferation and virulence of a variety of herpes viruses. Anabolic steroids have also been demonstrated by various studies to negatively affect cell-mediated immunity necessary to prevent viral infection. Thus, it is possible that anabolic steroids in conjunction with increased L-arginine intake may have precipitated a recurrent $\mathrm{HZO}$ in a previously healthy, immunocompetent individual.
\end{abstract}

\section{Introduction}

Anabolic-androgenic steroids (AAS), or performanceenhancing drugs, have been used by elite professional athletes and general fitness enthusiasts in order to increase strength and muscle growth. However, the prevalence of anabolic abuse within the USA is not known. Several factors may contribute to the underestimation of anabolic steroid users including insufficient drug tests, on and off cycling of AAS, and taboo or illegal connotation associated with AAS.

AAS comprises a group of synthetic and natural hormones which are structurally and functionally similar to testosterone. Despite the benefits associated with AAS, there are numerous well-known side effects including psychosis, organ damage (e.g., heart, liver, and kidney), hair loss, severe acne, increased risk of tendinitis or tendon rupture, and liver tumors [1]. Also, certain types of AAS have been documented to have immunosuppressive features, impairing $B$ and $\mathrm{T}$ cell functions necessary for viral infections $[2,3]$.

Herpes zoster or shingles is the product of the reactivation of latent varicella zoster virus (VZV). Reactivation of the virus is common in the elderly and immunocompromised, with the rate of incidence increasing in each decade of life and peaking around 80 years old. Approximately $30 \%$ of all individuals will develop at least one shingles outbreak in their lifetime [4]. VZV can also affect the eye during 
the involvement of the ophthalmic division of the fifth cranial nerve (V1), known as herpes zoster ophthalmicus (HZO).

Nevertheless, we noticed an unusual presentation of recurrent $\mathrm{HZO}$ in a 34 -year-old male, preceded by a 6 -week cycle of anabolic steroids and high-dose amino acid supplementation prior to each episode.

\section{Case Presentation}

A 34-year-old man with no past medical history presented to our clinic complaining of left eye pain and pressure for one week. He was referred by his primary care doctor for suspected HZO, who had started the patient on acyclovir $800 \mathrm{mg} 5$ times a day prior to his visit to our clinic.

The patient denied any relevant past medical history including diabetes and HIV. He denied smoking, alcohol, or illicit drug use. The patient also denied taking any immunosuppressant agents including prednisone. However, the patient was an active weightlifter who reported having completed a 6-week course of AAS two weeks prior to the onset of his symptoms. His regimen consisted of trenbolone $200 \mathrm{mg}$, deca-durabolin $200 \mathrm{mg}$, and testosterone $500 \mathrm{mg}$ a week (Table 1) along with a diet high in protein and supplemental amino acids including arginine. A diet recall averaged above 40 grams of L-arginine a day (Table 2).

On external exam, vesicles were noted over the left eyebrow and upper lid. Anterior segment exam was notable for decreased corneal sensation OS. Slit-lamp examination was remarkable for punctate staining and pseudodendrites at 6 o'clock, outside the visual axis OS. No anterior segment inflammation was noted with intraocular pressure within normal limits. The fundus exam was unremarkable for both eyes.

The patient was continued on oral acyclovir as well as moxifloxacin 0.5\% QID and prednisone 1\% QID OS which was tapered over a month. The patient was strongly encouraged to stop his AAS regiment as well as high-dose arginine diet/supplementation. HZO keratitis resolved over the course of a month.

Four months later, the patient presented to the clinic with new eye pain OS after completing another cycle of the above AAS and high-arginine diet. Uncorrected visual acuity was 20/40. Slit-lamp examination revealed deep stromal vessels with a $2 \times 2 \mathrm{~mm}$ infiltrate just inferior to the visual axis at 5 o'clock. Intraocular pressure and fundus exam were unremarkable. The patient was started on acyclovir $800 \mathrm{mg} 5$ times a day for the next seven days with prednisolone $1 \%$ QID. The patient was counseled on stopping AAS as well as the need for a lifelong prophylaxis dose of acyclovir. However, after interval improvement, the patient was lost to follow-up.

\section{Discussion}

HZO can occur with or without ocular involvement in 10$20 \%$ of patients with a vesicular rash in the V1 dermatome [5]. Ocular findings most commonly include conjunctivitis, episcleritis/scleritis, keratitis, uveitis, and less commonly
TABLE 1: The route, dosage, frequency, and schedule of anabolicandrogenic steroid (AAS) supplementation by the patient prior to each episode of HZO.

\begin{tabular}{|c|c|c|c|c|}
\hline $\begin{array}{l}\text { Anabolic } \\
\text { androgenic steroid }\end{array}$ & Route & Amount & Frequency & Cycle \\
\hline Trenbolone & Intramuscular & $200 \mathrm{mg}$ & $1 \mathrm{x}$ week & 4 \\
\hline Deca-durabolin & Intramuscular & $200 \mathrm{mg}$ & $1 \mathrm{x}$ week & $\begin{array}{c}\text { weeks } \\
\text { on }\end{array}$ \\
\hline Testosterone & Intramuscular & $500 \mathrm{mg}$ & $1 \mathrm{x}$ week & $\begin{array}{c}2 \\
\text { weeks } \\
\text { off }\end{array}$ \\
\hline
\end{tabular}

retinal necrosis which is often seen in immunocompromised patients [6].

VZV is considered a disease of late adulthood, with the rate of incidence increasing in each decade of life, especially when combined with immunocompromised individuals [7]. Although the majority of individuals affected by herpes zoster are over the age of 60 [8], recent trends show a decreasing mean age of onset which is likely due to widespread childhood varicella vaccination [9]. However, other risk factors have been documented for earlier age of onset including immunosuppression from either pharmacological or pathological etiologies (e.g., leukemia/lymphoma, HIV, transplant recipients, and corticosteroids or chemotherapy agents), autoimmune disorders, female gender, smoking, and diabetes [9].

In particular, smoking was the strongest risk factor for earlier age of onset, presenting on average 11.5 years earlier than nonsmokers [9]. Although approximately 30\% of all individuals will develop at least one shingles outbreak in their lifetime, recurrent zoster infections are uncommon, ranging from $1.3 \%$ to $6.2 \%$ [10].

Our patient was a young, healthy 34-year-old individual who developed a recurrent $\mathrm{HZO}$ keratitis. He was not an active smoker, diabetic, or immunocompromised via the numerous etiologies listed above. Thus, it is possible that other factors may have contributed to his clinical presentation.

As an active weightlifter, our patient supplemented his diet with high-dose amino acids as well as anabolic steroids. We previously documented a case of recurrent $\mathrm{HZO}$ in a young, immunocompetent individual, preceded by highdose L-arginine at $46.5 \mathrm{~g} /$ day [11]. L-arginine is a semiessential amino acid which has been found to have beneficial effects in wound healing, immune function, and metabolism at 4.2 to $20 \mathrm{~g} /$ day [12]. Nevertheless, the adverse effects of long-term supplementation above these recommended values have not been well studied [12].

L-Arginine also serves as an essential role in viral replication. Herpes simplex viruses (HSV-1 and HSV-2), varicellazoster virus (VZV), cytomegalovirus (CMV), and adenovirus require arginine to replicate [13-16]. In vitro studies have demonstrated a decrease in HSV 1-2 replication, cell-to-cell transmission, and virus-mediated cytopathic effects in mediums deficient in L-arginine [13, 17]. Arginase, an enzyme that degrades L-arginine to L-ornithine and urea, was also found to be increased tenfold in a murine model 
TABLE 2: A diet recall highlighting food and supplements containing high levels of L-arginine. The daily arginine intake ranged from 29.850.7 grams, averaging 40.2 grams/day. Arginine amount derived from the USDA National Nutrient Database (http://www.ars.usda.gov/ nutrientdata).

\begin{tabular}{lcc}
\hline Typical diet & Average amount & Arginine (grams) \\
\hline Dry roasted nuts (peanuts, almonds, or walnuts) & 2 cups & $7.65-10.13$ \\
Meat (chicken, fish, pork, or beef) & 4 cups & $9.6-24.0$ \\
Whole cooked eggs & 3 large & 1.22 \\
Cottage cheese & 1 cup & 2.56 \\
Rice & 2 cups & $\mathrm{Na}^{*}$ \\
Supplements (protein powder, preworkout drinks, and amino acids) & & 0.76 \\
Patient range & & $29.0-12.0$ \\
Normal range & $6.0-20.0$ \\
\hline
\end{tabular}

of HSV-1-induced stromal keratitis infection [17], potentially linking arginine concentrations with symptom resolution. Other researchers also found an accumulation of arginine in the corneal epithelium during herpetic infections, a finding which was attributed to increased viral virulence and replication [17]. Additionally, the use of topical arginase led to a resolution of the herpetic episode, supporting arginine's role in infection and disease progression [18].

Despite these instances where arginine was associated with viral proliferation, other studies have shown that arginine and its derivatives can be viricidal. Naito et al. showed that arginine was effective against inhibiting HSV-1 replication in moderate concentrations while Yamasaki et al. reported that the arginine derivative $\mathrm{N} \alpha$-Cocoyl-L-arginine ethyl ester was effective at inhibiting HSV extracellular virus particles and replication $[19,20]$. The contrasting results of these studies may be due to the variances of arginine being utilized. Isomers of arginine versus arginine complexes are likely to affect the structure and thus function of the amino acid. In most studies, supplementation of arginine did not exceed $30 \mathrm{~g} /$ day. Thus, there may be a critical threshold in which arginine dosage can lead to adverse effects which has not been clearly documented in the literature.

The other variable we believe may have influenced the recurrent episodes of HZO in our patient is his use of AAS. Anabolic steroids are not a commonly associated risk factor in HZV outbreaks. Nevertheless, these hormones have been documented to cause immunosuppressive effects. Grossman and Roselle found that one of the biological actions of androgen steroid hormones is the modulation of the immune system through the regulation of $\mathrm{T}$ lymphocyte function [2]. In particular, AAS with intact steroid nucleus exhibited a persistent immunosuppressive effect while those with nuclear alterations elicited a delayed immunostimulatory effect [2]. This distinction is important in this case, as our patient reported only taking AAS that had intact steroid nuclei.

The cells most adversely influenced by AAS with an intact steroid nucleus are lymphocytes (T cells) whose differentiation and proliferation are curtailed by reduced natural killer cytotoxic activity and the diminished production of certain cytokines such as IL-2, interferon-gamma (IFN- $\gamma$ ), and corticotropin [21]. These findings are supported in a sep- arate study examining the impact of oxymetholone, another AAS with an intact steroid nucleus. Researchers found a $15 \%$ decrease in cytotoxic $\mathrm{T}$ cell activity measured in mice taking $300 \mathrm{mg} / \mathrm{kg}$ of oxymetholone for fourteen days, indicating that cell-mediated immunity was impaired following exposure [22]. Another study analyzed the role of testosterone in response to the influenza vaccine in animals. Furman et al. found that testosterone was immunosuppressive in vivo, downregulating transcription factors (such as FOS and JUN) implicated in immune activation [3]. One group of experiments demonstrated that orchiectomies of mice led to increased protection against viral, fungal, bacterial, and parasitic infestations [23]. Orchiectomized animals also rejected allografts more rapidly and had accelerated graftversus-host reactions [23].

Lastly, the role of VZV reactivation within immunosuppressed patients has been analyzed. Patients with depressed cell-mediated immune function from hematopoietic stem cell transplantation were assessed for VZV reactivation while receiving intravenous $\gamma$-globulin antibodies. It was observed that the incidence of shingles markedly increased in the study patients, highlighting the importance of cell-mediated immune function in preventing viral reactivation [24].

Therefore, we hypothesize that AAS used by the patient may have compromised his cell-mediated immunity necessary to prevent VZV reactivation. Also, high-dose Larginine supplementation may have also facilitated increased viral replication and virulence within a potentially immunocompromised individual. Nevertheless, we have only documented two similar cases and require further studies to deem if a real association exists.

\section{Conclusion}

In summary, we present a 34-year-old, healthy individual who developed recurrent HZO preceded by anabolic steroid abuse and high-dose L-arginine supplementation. In vitro experiments have demonstrated conflicting results between stimulatory versus inhibitory effects on herpes virus replication and virulence with L-arginine. Although data on arginine supplementation is limited, no long-term studies have documented the effects of high-dose arginine supplementation, greater than 20 grams a day, on immune function. 
Additionally, the immunosuppressive effects of AAS with intact steroid nucleus on the cell-mediated immune response have been documented in the literature. Increased rates of zoster reactivation have been witnessed in individuals who lack cell-mediated immune systems. Nevertheless, larger, prospective studies are needed to deem if a true association exists between recurrent $\mathrm{HZO}$, L-arginine, and AAS.

\section{Consent}

The patient consented to publication of the case in writing. This report does not contain any personal information that could lead to the identification of the patient.

\section{Disclosure}

All authors attest that they meet the current ICMJE criteria for Authorship.

\section{Conflicts of Interest}

The following authors have no financial disclosures or conflicts of interest: SAL, AG, RAG, SMC, MB, SA, TDL. The abstract was presented as a digital poster at the 2020 American Society of Cataract and Refractive Surgeons.

\section{References}

[1] H.-L. KRÜSKEMPER, "Side effects of anabolic steroids," in Anabolic Steroids, pp. 167-183, Academic Press, Cambridge, MA, USA, 1968.

[2] C. L. Mendenhall, C. J. Grossman, G. A. Roselle et al., "Anabolic steroid effects on immune function: differences between analogues," The Journal of Steroid Biochemistry and Molecular Biology, vol. 37, no. 1, pp. 71-76, 1990.

[3] D. Furman, B. P. Hejblum, N. Simon et al., "Systems analysis of sex differences reveals an immunosuppressive role for testosterone in the response to influenza vaccination," Proceedings of the National Academy of Sciences, vol. 111, no. 2, pp. 869874, 2014.

[4] Shingles, Centers for Disease Control and Prevention, Centers for Disease Control and Prevention, 2019, http://www.cdc .gov/shingles/surveillance.html.

[5] T. J. Liesegang, "Herpes zoster ophthalmicus natural history, risk factors, clinical presentation, and morbidity," Ophthalmology, vol. 115, no. 2, pp. S3-12, 2008.

[6] B. P. Yawn, P. C. Wollan, J. L. St Sauver, and L. C. Butterfield, "Herpes zoster eye complications: rates and trends," Mayo Clinic Proceedings, vol. 88, no. 6, pp. 562-570, 2013.

[7] R. P. Insinga, R. F. Itzler, J. M. Pellissier, P. Saddier, and A. A. Nikas, "The incidence of herpes zoster in a United States administrative database," Journal of General Internal Medicine, vol. 20, no. 8, pp. 748-753, 2005.

[8] R. Harpaz, I. R. Ortega-Sanchez, J. F. Seward, and Advisory Committee on Immunization Practices (ACIP) Centers for Disease Control and Prevention (CDC), "Prevention of herpes zoster: recommendations of the Advisory Committee on Immunization Practices (ACIP)," MMWR Recomm Rep, vol. 57, no. RR-5, pp. 1-30, 2008.
[9] A. Y. Chan, C. D. Conrady, K. Ding, J. D. Dvorak, and D. U. Stone, "Factors associated with age of onset of herpes zoster ophthalmicus," Cornea, vol. 34, no. 5, pp. 535-540, 2015.

[10] B. P. Yawn, P. C. Wollan, M. J. Kurland, J. L. St Sauver, and P. Saddier, "Herpes zoster recurrences more frequent than previously reported," Mayo Clinic Proceedings, vol. 86, no. 2, pp. 88-93, 2011.

[11] S. A. LoBue, P. Tailor, S. M. Carlson et al., "Recurrent herpes zoster ophthalmicus in a young, healthy individual taking high doses of 1-arginine," American Journal of Ophthalmology Case Reports, vol. 16, p. 100547, 2019.

[12] A. Shao and J. N. Hathcock, "Risk assessment for the amino acids taurine, L-glutamine and L-arginine," Regulatory Toxicology and Pharmacology, vol. 50, no. 3, pp. 376-399, 2008.

[13] R. W. Tankersley, "Amino acid requirements of herpes simplex virus in human cells," Journal of Bacteriology, vol. 87, no. 3, pp. 609-613, 1964.

[14] E. Gönczöl, I. Boldogh, and L. Váczi, "Effect of arginine deficiency on the reproduction of human cytomegalovirus," Acta Microbiologica Academiae Scientiarum Hungaricae, vol. 22, no. 3, pp. 263-270, 1975.

[15] R. Wigand and G. Kümel, "Amino acid requirement of adenovirus multiplication," The Journal of General Virology, vol. 39, no. 2, pp. 281-292, 1978.

[16] M. D. Sanchez, A. C. Ochoa, and T. P. Foster, "Development and evaluation of a host-targeted antiviral that abrogates herpes simplex virus replication through modulation of arginine-associated metabolic pathways," Antiviral Research, vol. 132, pp. 13-25, 2016.

[17] S. K. Mistry, M. Zheng, B. T. Rouse, and S. M. Morris, "Induction of arginases I and II in cornea during herpes simplex virus infection," Virus Research, vol. 73, no. 2, pp. 177-182, 2001.

[18] I. L. Kahán, K. Hajas, and A. Halász, “The significance of the arginine and arginase of tears in experimentally-induced herpes simplex corneae," Albrecht von Graefes Archiv für Klinische und Experimentelle Ophthalmologie, vol. 209, no. 3, pp. 219-224, 1979.

[19] T. Naito, H. Irie, K. Tsujimoto, K. Ikeda, T. Arakawa, and A. H. Koyama, "Antiviral effect of arginine against herpes simplex virus type 1," International Journal of Molecular Medicine, vol. 23, no. 4, pp. 495-499, 2009.

[20] H. Yamasaki, K. Tsujimoto, K. Ikeda, Y. Suzuki, T. Arakawa, and A. H. Koyama, "Antiviral and virucidal activities of $\mathrm{n} \alpha$ cocoyl-L-arginine ethyl ester," Adv Virol, vol. 2011, pp. 1-6, 2011.

[21] T. K. Hughes, E. Fulep, T. Juelich, E. M. Smith, and G. J. Stanton, "Modulation of immune responses by anaboloic androgenic steroids," International Journal of Immunopharmacology, vol. 17, pp. 857-863, 1995.

[22] N. A. Karrow, J. A. McCay, R. Brown et al., "Oxymetholone modulates cell-mediated immunity in male B6C3F1 mice," Drug and Chemical Toxicology, vol. 23, no. 4, pp. 621-644, 2000.

[23] S. A. Ahmed and N. Talal, "Effects of sex hormones on immune responses and autoimmune diseases: an update," American Journal of Pathology, pp. 333-337, 1999.

[24] M. Oxman, "Herpes zoster pathogenesis and cell-mediated immunity and immunosenescence," Journal of the American Osteopathic Association, vol. 109, no. 6, pp. S13-S17, 2009. 